\title{
Obstetric Brachial Plexus Palsy: The Mallet Grading System for Shoulder Function-Revisited
}

\author{
M. M. Al-Qattan and A. A. F. El-Sayed \\ Department of Surgery and Obstetrics, King Saud University, P.O. Box 18097, Riyadh 11415, Saudi Arabia \\ Correspondence should be addressed to M. M. Al-Qattan; moqattan@hotmail.com
}

Received 31 October 2013; Revised 27 December 2013; Accepted 28 December 2013; Published 5 January 2014

Academic Editor: Roberto Cirocchi

Copyright (C) 2014 M. M. Al-Qattan and A. A. F. El-Sayed. This is an open access article distributed under the Creative Commons Attribution License, which permits unrestricted use, distribution, and reproduction in any medium, provided the original work is properly cited.

\begin{abstract}
The Mallet grading system is a commonly used functional scoring system to assess shoulder abduction/external rotation deficits in children with obstetric brachial plexus palsy. One feature of the Mallet score is that each grade is translated into certain degrees of deficiencies in both shoulder abduction and external rotation. The aim of the current study is to investigate the percentage of children in which the Mallet score could not be applied because of a discrepancy between the deficiency of shoulder abduction and shoulder external rotation. The study group included 50 consecutive unoperated older children (over 5 years of age) with Erb's palsy and deficits in shoulder movements. The Mallet score could be applied in 40 cases (80\%). In the remaining 10 cases (20\%), the Mallet score could not be applied either because shoulder abduction had a better grade than the grade of shoulder external rotation $(n=7)$ or vice versa $(n=3)$. It was concluded that documenting the deficits in shoulder abduction and external rotation are best done separately and this can be accomplished by using other grading systems.
\end{abstract}

\section{Introduction}

The most common secondary deformity in obstetric brachial plexus Erb's palsy is seen at the shoulder; the most common shoulder deformity is the deficiency of shoulder abduction/external rotation [1].

There are different methods of scoring shoulder abduction/external rotation of the shoulder such as the Toronto muscle grading system [2], the King Saud University grading system [3], and the Mallet grading system (Table 1). The Mallet grading remains the most commonly used system in several obstetric brachial plexus centers [4-6]. One feature of the Mallet score is that each grade is translated into certain degrees of deficiencies in both shoulder abduction and external rotation. The authors noted that the Mallet score could not be applied to several children with obstetric ERb's palsy mainly because there is a discrepancy in the Mallet grade of shoulder abduction and the grade of shoulder external rotation.

The aim of this study is to investigate the percentage of children in which the Mallet score could not be applied to assess shoulder function in a series of unoperated older children (over 5 years of age) with obstetric brachial plexus Erb's palsy. Older children were selected because the Mallet score requires special tasks that are difficult to apply to infants and younger children.

\section{Patients and Methods}

Fifty consecutive unoperated children (over 5 years of age) with shoulder deficits were selected for the study. All children were seen at our obstetric brachial plexus clinic [7]. Selection criteria were Erb's obstetric palsy, no previous surgery, age over 5 years of age, active elbow flexion (over 100 degrees) against resistance, and adequate data documenting the shoulder deficits. The Mallet score (Table 1) was documented to assess shoulder function if possible. If the Mallet score could not be applied, the reason for discrepancy between shoulder abduction and external rotation is documented. The percentage of the latter group of children is also calculated. 
TABLE 1: The Mallet grading system for shoulder function.

\begin{tabular}{|c|c|}
\hline Grade & Description \\
\hline $\mathrm{I}$ & Flail shoulder \\
\hline II & $\begin{array}{l}\text { Active abduction } \leq 30^{\circ} \\
\text { Zero degrees of external rotation } \\
\text { Hand to back of neck impossible } \\
\text { Hand to back impossible } \\
\text { Hand to mouth with marked trumpet sign }\end{array}$ \\
\hline III & $\begin{array}{l}\text { Active abduction } 30-90^{\circ} \\
\text { External rotation up to } 20^{\circ} \\
\text { Hand to back of neck with difficulty } \\
\text { Hand to back with difficulty } \\
\text { Hand to mouth possible with partial trumpet sign (over } \\
40^{\circ} \text { of shoulder abduction) }\end{array}$ \\
\hline IV & $\begin{array}{l}\text { Active abduction over } 90^{\circ} \\
\text { External rotation over } 20^{\circ} \\
\text { Hand to back of neck easy } \\
\text { Hand to back easy } \\
\text { Hand to mouth easy with less than } 40^{\circ} \text { of shoulder } \\
\text { abduction }\end{array}$ \\
\hline $\mathrm{V}$ & Normal shoulder \\
\hline
\end{tabular}

\section{Results}

The mean age of the study group $(n=50)$ was 8 years (range 5-15 years). All children had cephalic presentation and a history of difficult delivery. Forty-four of these children presented late to our clinic for correction of secondary shoulder deformity. The remaining six children were initially seen in our clinic soon after birth, but no primary exploration was done because children recovered active elbow flexion against gravity prior to 4 months of age. These six cases were then lost for followup for 5-8 years and then presented back to our clinic with the shoulder deficits.

Table 2 summarizes the results. The Mallet score could be applied to assess the shoulder deficits in 40 cases (80\%). In these cases, the deficit of shoulder abduction coincided with the deficit of shoulder external rotation in each case according to the criteria put by the score in Table 1 . In 10 cases (20\%), the Mallet grading system could not be applied either because shoulder abduction had a better grade than the grade of shoulder external rotation $(n=7)$ or vice versa $(n=3)$.

\section{Discussion}

The current study is the first study that assesses that applicability of the Mallet score in children with Erb's palsy. Clinically, the surgeon tailors the indications of surgery depending on the degree of the deficit of every joint motion. However, the Mallet score is frequently used in research papers to assess the combined deficits at both shoulder abduction and external rotation. It is of concern that $20 \%$ of children will have a discrepancy in the Mallet score of shoulder abduction and external rotation. Hence, for research papers, it seems that it is more logical to document the deficits in shoulder abduction and the deficits in shoulder external rotation separately; this can be accomplished by using other grading systems $[2,3]$.

One observation of our results is that none of the 50 children had Grade I shoulder deficit (flail shoulder). A flail shoulder is usually seen in obstetric palsy following breech delivery with C5/C6 avulsion [8]. All our children in our study group had a cephalic presentation.

In seven of the 10 children in whom the Mallet score could not be applied to, shoulder abduction grade was better than the grade of shoulder external rotation. This suggests that the suprascapular nerve sustained a higher grade of injury than the posterior division of the upper trunk. The most unusual case was Case $\neq 7$ (Table 2) in whom shoulder abduction was normal (Grade V) while the Mallet grade of shoulder external rotation was only Grade II.

The deltoid muscle is the primary abductor of the shoulder; the infraspinatus muscle is the primary shoulder external rotator. Anatomically, both of these muscles are supplied by the fifth cervical root (C5). However, the nerve fibers supplying the deltoid muscle are carried through the posterior division of the upper trunk, while the nerve fibers supplying the infraspinatus are carried through the suprascapular branch of the upper trunk. Obstetric paralysis is mainly caused by traction of the nerve roots during delivery [9], and severity of intrapartum forces on the roots of the brachial plexus will vary greatly depending on fetal factors (such as fetal macrosomia and fetal presentation), maternal factors (such as the degree of cephalopelvic disproportion), and delivery factors (such as the use of instrumental delivery and maneuvers used to manage shoulder dystocia) [10]. Furthermore, the cadaveric studies of G. A. Brunelli and G. R. Brunelli [11] showed that the direction of force as well as the anatomical position of each root or branch of the brachial plexus will also determine the degree of axonal damage from an externally exerted force on the neck. Since the deltoid and infraspinatus muscles are supplied by two different branches of the upper trunk, the force (and hence the degree of axonal damage) may be different on each branch, explaining the differences in the deficits of shoulder abduction/external rotation in the same patient.

In conclusion, the Mallet score could not be applied to $20 \%$ of unoperated children with obstetric brachial plexus palsy because of the discrepancy of the grade of shoulder abduction and the grade of shoulder external rotation in the same patient. This suggests that the intrapartum forces on the posterior division of the upper trunk may vary from the forces on the suprascapular branch of the upper trunk in the same patient.

\section{Conflict of Interests}

There is no conflict of interests.

\section{Authors' Contribution}

Both authors participated in data collection and preparation of the paper. 
TABLE 2: The Mallet grading system applied to 50 children with Erb's obstetric palsy with shoulder deficits.

\begin{tabular}{|c|c|c|c|}
\hline \multirow[t]{2}{*}{$\begin{array}{l}\text { Group I ( } n=40) \text { : Mallet grading system } \\
\text { could be applied to assess the shoulder deficits }\end{array}$} & \multicolumn{3}{|c|}{$\begin{array}{l}\text { Group II }(n=10) \text { Mallet grading system could not be applied to assess the } \\
\text { shoulder deficits because of discrepancy in the grade of }\end{array}$} \\
\hline & & Shoulder abduction grade & Shoulder external rotation grade \\
\hline Grade $\mathrm{I}=$ no cases & Case 1 & III & II \\
\hline Grade II = 13 children & Case 2 & III & II \\
\hline Grade III = 15 children & Case 3 & IV & III \\
\hline Grade IV = 12 children & Case 4 & IV & II \\
\hline \multirow[t]{6}{*}{ Grade $V=$ no cases } & Case 5 & IV & III \\
\hline & Case 6 & IV & III \\
\hline & Case 7 & $\mathrm{~V}$ & II \\
\hline & Case 8 & III & IV \\
\hline & Case 9 & II & III \\
\hline & Case 10 & II & III \\
\hline
\end{tabular}

\section{Acknowledgment}

This project was funded by the College of Medicine Research Center, Deanship of Scientific Research, King Saud University, Riyadh, Saudi Arabia.

\section{References}

[1] M. M. Al-Qattan, "Classification of secondary shoulder deformities in obstetric brachial plexus palsy," Journal of Hand Surgery, vol. 28, no. 5, pp. 483-486, 2003.

[2] H. M. Clarke and C. G. Curtis, "An approach to obstetrical brachial plexus injuries," Hand Clinics, vol. 11, no. 4, pp. 563580, 1995.

[3] M. M. Al-Qattan, "Assessment of the motor power in older children with obstetric brachial plexus palsy," Journal of Hand Surgery, vol. 28, no. 1, pp. 46-49, 2003.

[4] F. J. G. Cuesta, F. L. Prats, F. J. G. Lopez, and J. B. Sitja, “The role of bone operations as palliative surgical treatment for the sequelae of obstetrical brachial paralysis in the shoulder," Acta Orthopaedica Belgica, vol. 48, no. 5, pp. 757-761, 1982.

[5] A. Gilbert, "Long-term evaluation of brachial plexus surgery in obstetrical palsy," Hand Clinics, vol. 11, no. 4, pp. 583-594, 1995.

[6] L. Nualart, N. Cassis, and R. Ochoa, "Functional improvement with the Sever L'Episcopo procedure," Journal of Pediatric Orthopaedics, vol. 15, no. 5, pp. 637-640, 1995.

[7] M. M. Al-Qattan, "The first multi-disciplinary obstetrical brachial plexus clinic in Saudi Arabia," Journal of Hand Surgery, vol. 21, no. 1, pp. 124-125, 1996.

[8] G. Geutjens, A. Gilbert, and K. Helsen, "Obstetric brachial plexus palsy associated with breech delivery-a different pattern of injury," Journal of Bone and Joint Surgery B, vol. 78, no. 2, pp. 303-306, 1996.

[9] S. H. Mehta and B. Gonik, "Neonatal brachial plexus injury: obstetrical factors and neonatal management," Journal of Pediatric Rehabilitation Medicine, vol. 4, no. 2, pp. 113-118, 2011.

[10] S. K. Doumouchtsis and S. Arulkumaran, "Is it possible to reduce obstetrical brachial plexus palsy by optimal management of shoulder dystocia," Annals of the New York Academy of Sciences, vol. 1205, pp. 135-143, 2010.
[11] G. A. Brunelli and G. R. Brunelli, "A fourth type of brachial plexus lesion: the intermediate (C7) palsy," Journal of Hand Surgery B, vol. 16, no. 5, pp. 492-494, 1991. 


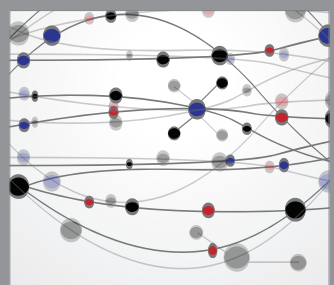

The Scientific World Journal
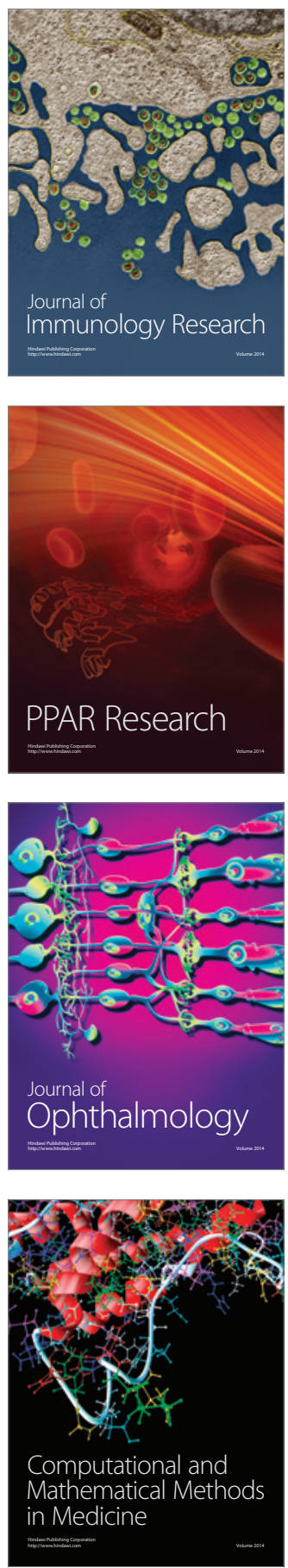

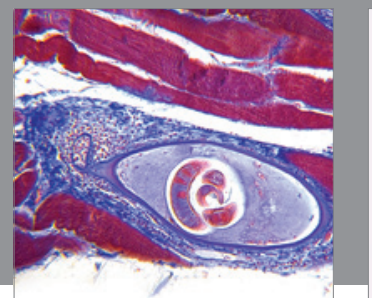

Gastroenterology

Research and Practice
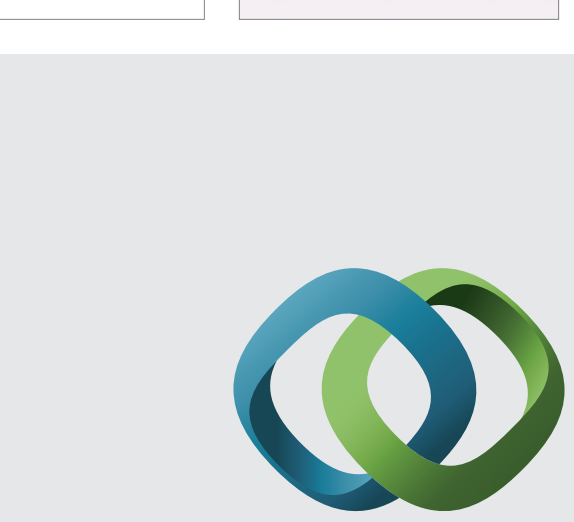

\section{Hindawi}

Submit your manuscripts at

http://www.hindawi.com
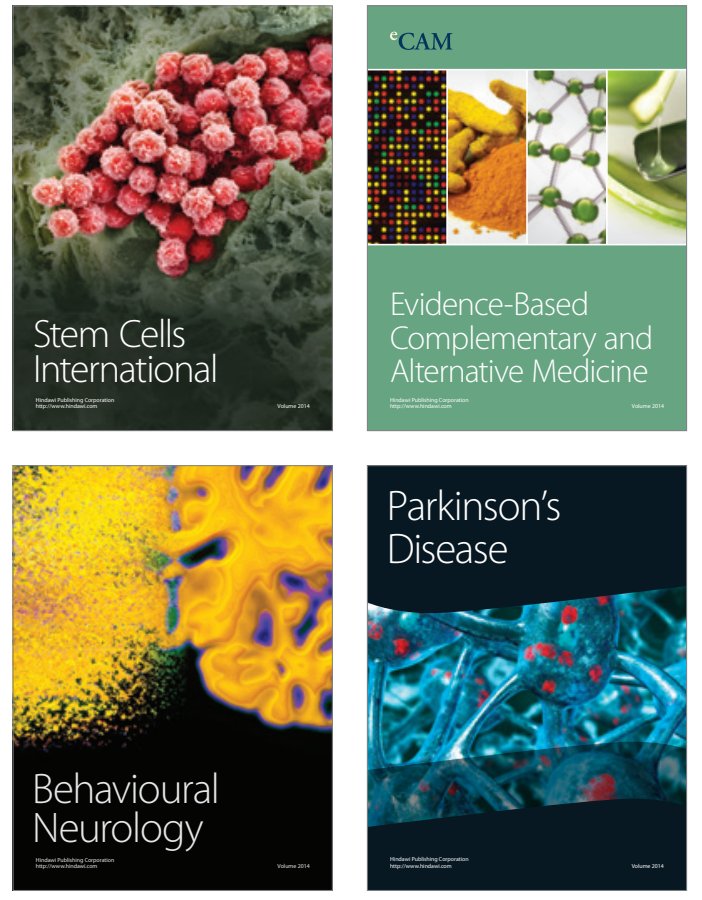
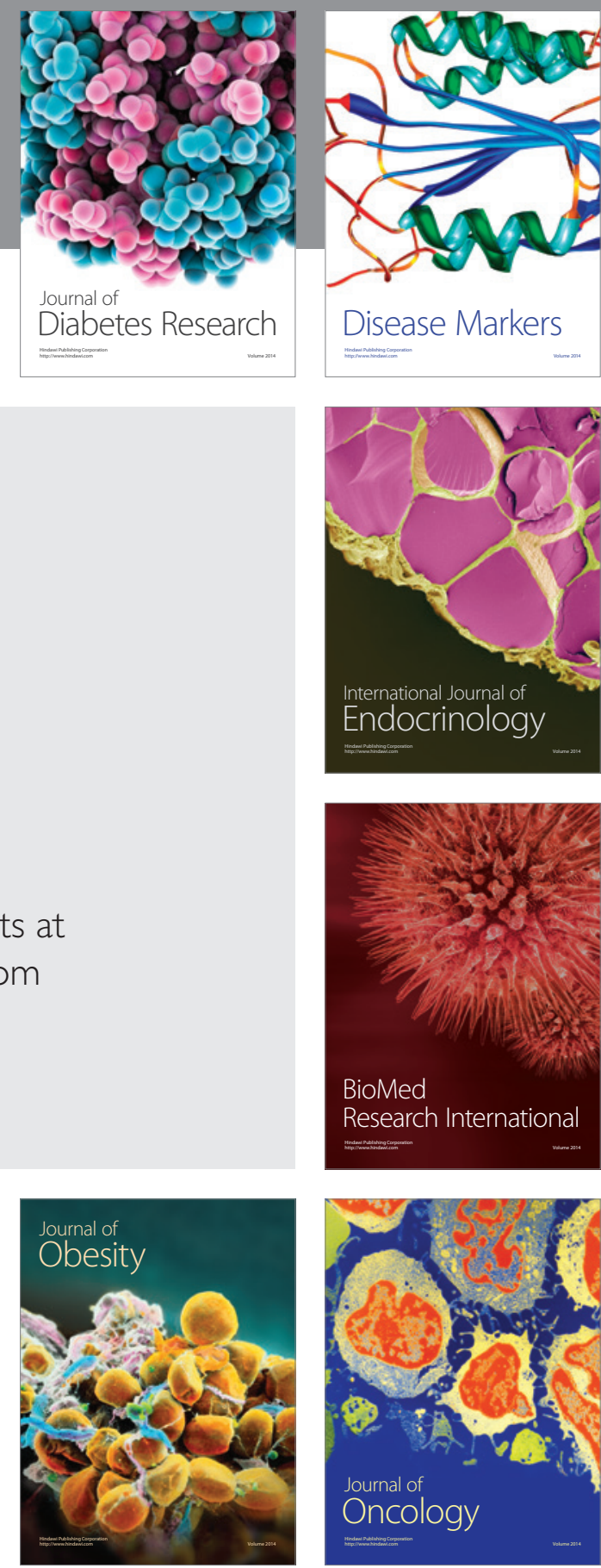

Disease Markers
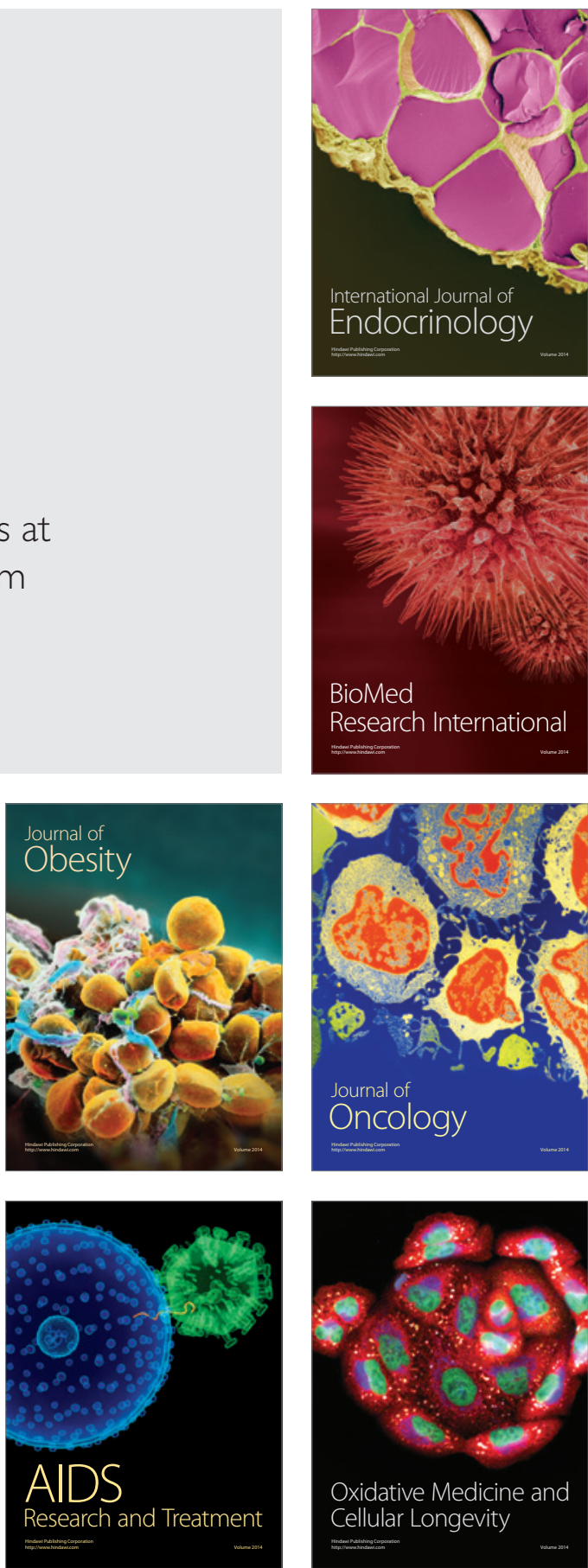